\title{
8 The Potential of Microwave Treatment to Kill Weed Plants
}

\subsection{Introduction}

The effect of radio frequency and microwave radiation on plants has interested researchers for some time, with several experiments dating to the 1920's (Ark \& Parry, 1940). Magone (1996) studied duckweed (Spirodela polyrhiea) grown in flasks some $2 \mathrm{~km}$ from a radio station transmitter. The frequency and intensity of the radiation

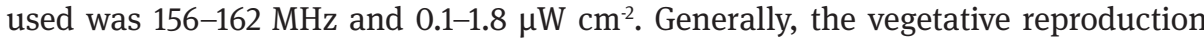
rate of plants that were exposed to the electromagnetic radiation for between 24 hours and 88 hours was accelerated by between 105\% and 195\%, compared with the control plants, during the first 20 days after exposure. Exposure of plants that were just beginning formation exhibited slightly reduced vegetative growth rate. This phenomenon has also been observed in yeast exposed to 40 to $60 \mathrm{GHz}$ microwave fields by Grundler, Keilmann, and Fröhlich (1977) and by Horikoshi, Hasegawa, and Suzuki (2017), who showed that plant growth and the onset of reproductive growth can be significantly enhanced by very short exposure to very low intensity, $2.45 \mathrm{GHz}$ microwave irradiation.

It is likely that this increased growth and particularly the onset of reproductive growth is a stress response in the plant. Controlled deficit irrigation (Zapata-Sierra \& Manzano-Agugliaro, 2017) is a more conventional strategy, which also achieves a reproductive response in plants due to the release of stress hormones. Controlled deficit irrigation allows parts of the root zone to dry out while other parts of the root zone are watered. Watering is usually alternated around the root zone, so that the roots in the deficit area are not compromised.

Application of very low level electromagnetic fields seems to have a more beneficial effect on the plants than simply allowing heat to dry the root zones. While studying the influence of microwave radiation on the plant cell membrane transport system activity, Petrov, Moiseeva, and Morozova (1991) found that membrane potential difference change deviation was the opposite to that induced by traditional heating, resulting in a positive response in plant growth. Although this is a fascinating phenomenon, it is not the focus of this work.

Skiles (2006) conducted an experiment where alfalfa was exposed to continuous microwave energy at $2.45 \mathrm{GHz}$ with intensities of $0.5-1.2 \mathrm{~mW} \mathrm{~cm}^{-2}$. After 7 weeks, the plants were harvested and fresh weight and dry weight were measured. There was no difference between the control and the microwave treated plants.

Wayland, Merkle, Davis, Menges, and Robinson (1975) demonstrated that microwave energy, with an energy density of $35 \mathrm{~J} \mathrm{~cm}^{-2}$ or more significantly damaged or killed growing plants. Values of 77,800 and $1600 \mathrm{~J} \mathrm{~cm}^{-2}$ have all been quoted as the minimum energy necessary for effective weed control (Hightower, Burdette, \& 
Burns, 1974; Wayland et al., 1975). Microwave radiation has several advantages when used to treat weeds. These include rapid penetration to all parts of the plant, without leaving any residue after application. The ability to kill herbicide resistant plants without disturbing the soil or adjacent crop plants, because microwave energy can be specifically focused on the target plants (Diprose, Benson, \& Willis, 1984). Microwave radiation is not affected by wind or rain. This extends the periods of application, compared to conventional spraying methods and has the potential to overcome crop yield losses due to treatment timeliness issues.

It is apparent that very small doses of electromagnetic energy can induce stress hormone responses in plants, which lead to improved reproductive production, while larger doses cause damage to plants. In weed management, the objective is to selectively damage unwanted plants.

\subsection{Early Experimental Prototypes}

Early work by Brodie and colleagues (Brodie, Botta, \& Woodworth, 2007; Brodie et al., 2009) used a modified microwave oven, with a wave guide and horn antenna feeding through and out of the oven cavity to apply energy to plants and the soil. The microwave oven (Sanyo Electric Co., $800 \mathrm{~W}$, size $46 \times 31 \times 28 \mathrm{~cm}$ ) used a rectangular ( $86 \times 43 \mathrm{~mm}$ internal dimensions) wave-guide to channel the microwave energy from the oven's $2.4 \mathrm{GHz}$ magnetron to a pyramidal horn antenna outside of the oven (Figure 8.1). The horn (aperture dimensions of $180 \times 90 \mathrm{~mm}$ and a length of $180 \mathrm{~mm}$ ) was attached to the wave-guide via a $90^{\circ}$ elbow. The prototype was used in many plant and soil heating experiments between 2007 and about 2010.

The original prototype, shown in Figure 8.1, was difficult to work with in field conditions, so a more flexible arrangement was devised (Figure 8.2). This system is more compact, with a housing and wave guide launcher that holds a 900 to 1200 $\mathrm{W}$ magnetron. This prototype is still wired into a microwave oven, replacing the connection to the oven's magnetron; therefore, the oven's voltage doubler circuit and electronic controls can still control the activity of the prototype's magnetron. The magnetron, located in the housing above the horn antenna, is cooled by an electric fan in the wall of the housing. This prototype design is still being used for experimental work.

Both early prototypes were useful for static experiments on pots and in the field; however, mobility is needed to test microwave weed control in field conditions. When funding became available, a trailer mounted microwave prototype was developed (Figure 8.3). This system has four fixed output $2 \mathrm{~kW}$ microwave generators operating at $2.45 \mathrm{GHz}$. It uses switched-mode power supplies to operate the water-cooled magnetron heads. The magnetron heads can be independently operated from a control panel in the side of the switching cabinet at the front of the trailer. The trailer system has been 


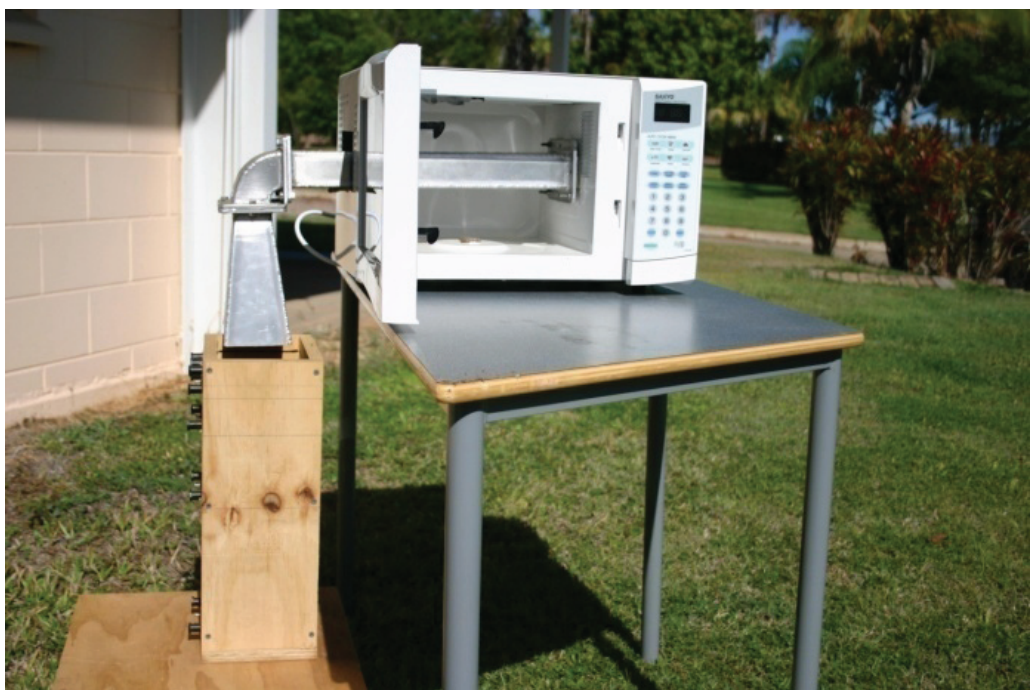

Figure 8.1: Prototype system, fed from the magnetron of a $800 \mathrm{~W}$ microwave oven (Source: Bebawi et al., 2007).

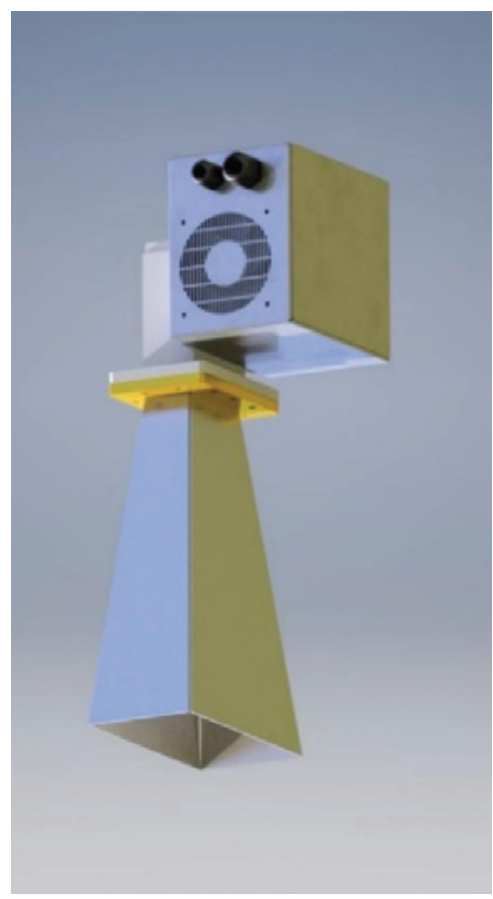

Figure 8.2: Rendering of the second prototype system, with a $900 \mathrm{~W}$ magnetron. The magnetron is wired into the voltage doubler circuit of a normal microwave oven via a $2 \mathrm{~m}$ long cable. 

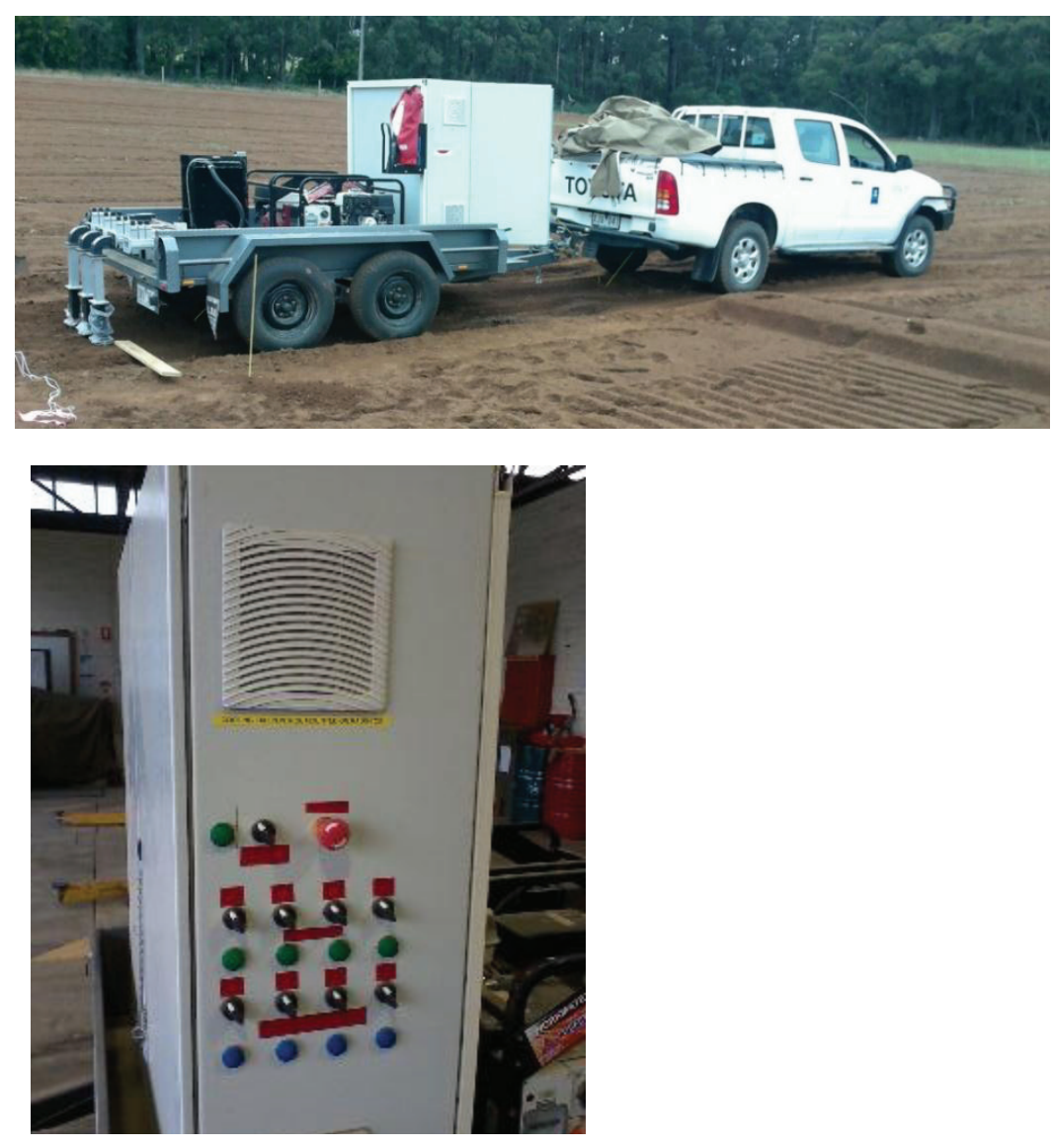

Figure 8.3: Prototype four by $2 \mathrm{~kW}$ microwave weed killer (above) with details of the control panel (below).

used for both static experiments on potted specimens and for moving experiments in field conditions.

\subsubsection{Static Experiments on Plants}

Potted plants have been treated with all the microwave prototypes. Experiments have been conducted for the following species: annual ryegrass (Lolium rigidum); barley grass (Hordeum vulgare L.); barnyard grass (Echinochloa crus-galli); fleabane (Conyza bonariensis L.); marshmallow (Malva parviflora L.); prickly paddy melon (Cucumis myriocarpus); and wild oat (Avena fatua) (Brodie, Hamilton, \& Woodworth, 2007; Brodie \& Hollins, 2015; Brodie, Ryan, \& Lancaster, 2012). In each case, both pot 
trials and in-situ field experiments were conducted for each species. Because of the potential hazard of directly measuring the microwave field strength in the aperture of the horn antenna, applied microwave energy, at ground level was determined using the models developed in Chapter 7.

In most cases the dose response for plant survival, as a function of applied microwave energy $(\Psi)$, was described by:

$$
S=a \bullet \operatorname{erfc}[\mathrm{b} \bullet(\Psi-\mathrm{c})]
$$

Where $S$ is the survival fraction of the treated population, $\Psi$ is the microwave energy density at ground level $\left(\mathrm{J} \mathrm{cm}^{-2}\right), \operatorname{erfc}(x)$ is the Gaussian complementary error function of $\mathrm{x}$, and $\mathrm{a}, \mathrm{b}$, and $\mathrm{c}$ are constants to be determined by regression for each experiment and species.

Equation (8.1) assumes that the individual plant responses to microwave irradiation are normally distributed, because the Gaussian Error functions represent the cumulative response of the population (i.e.: $\operatorname{erfc}(z)=\frac{1}{\sqrt{2 \pi}} \int_{z}^{\infty} e^{-\frac{t^{2}}{2}} \cdot d t$ - which is the integral of a normally distributed individual plant responses. It is effectively the cumulative response of the population).

Ryegrass plants show a double response to microwave treatment (Figure 8.4 - top left), with some efficacy at low application energy; however, $100 \%$ mortality required $600 \mathrm{~J} \mathrm{~cm}^{-2}$ of microwave energy at the soil surface. This is probably because grasses have their apical meristem at the base of the plant in or near the soil surface, where it is slightly protected from microwave heating by the leaves above and the surrounding soil. This is important to consider when designing an effective microwave applicator system for microwave weed management in cropping systems. The dose response for ryegrass is described by:

$$
S=0.58 \bullet \operatorname{erfc}\left[0.013\left(\mathrm{E}+1.24 \times 10^{-7}\right)\right]+0.174 \bullet \operatorname{erfc}[0.0097(E-448.4)]
$$

The $r^{2}$ value for this function is 0.72 . The results from the second repetition of this experiment were also the same as the first.

Figure 8.4 shows the response curves for four of the species tested during these experiments. It is apparent that some species are more susceptible to microwave treatment than others. Table 8.1 summarises the response parameters for the different test species and indicates the lethal doses for 50\% $\left(\mathrm{LD}_{50}\right)$ and $90 \%\left(\mathrm{LD}_{90}\right)$ weed control.

\subsubsection{Moving Trailer Experiments}

A novel antenna, which redirects the microwave energy horizontally rather than vertically, was developed (Brodie, Torkovnikov, \& Farrell, 2016). This antenna was connected to the prototype trailer (Figure 8.3) so that the microwave applicators was 

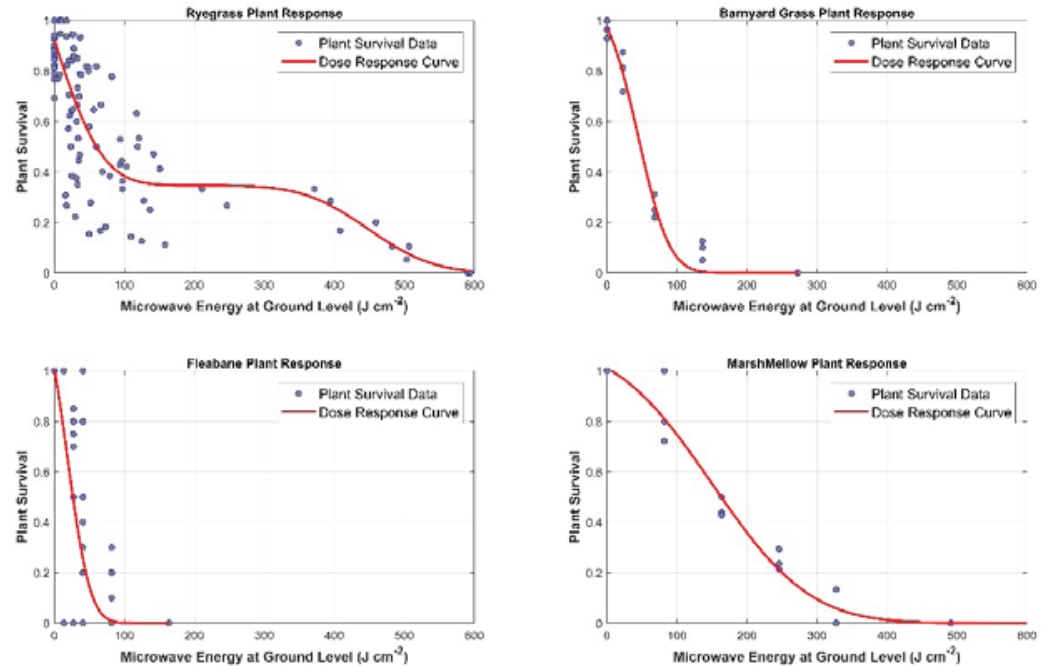

Figure 8.4: Dose response curves for microwave treatment of four species of weed plant using a horn antenna. Dose curves are calculated using equations (8.1) and (8.2).

Table 8.1: Equation coefficients, goodness of fit $\left(R^{2}\right), L_{50}$, and $L D_{90}$ for weed plant survival as a function of microwave energy applied to the soil surface.

\begin{tabular}{|c|c|c|c|c|c|c|c|c|c|}
\hline \multirow[t]{2}{*}{ Species } & \multicolumn{6}{|c|}{ Coefficients } & \multirow[t]{2}{*}{$\mathbf{R}^{2}$} & \multirow{2}{*}{$\begin{array}{l}\mathrm{LD}_{50} \\
\left(\mathrm{~J} \mathrm{~cm}^{-2}\right)\end{array}$} & \multirow{2}{*}{$\begin{array}{l}\mathrm{LD}_{90} \\
(\mathrm{~J} \mathrm{~cm}-2)\end{array}$} \\
\hline & a & b & c & d & e & f & & & \\
\hline Annual Ryegrass & 0.576 & 0.013 & $1.24 \mathrm{E}-07$ & 0.174 & 0.01 & 448.4 & 0.72 & 60 & 480 \\
\hline Barnyard grass & 0.54 & 0.02 & 44.7 & - & - & - & 0.98 & 48 & 91 \\
\hline Barley Grass & 0.56 & 0.022 & 40.92 & - & - & - & 0.99 & 45 & 84 \\
\hline Brome Grass & 0.58 & 0.012 & 65.19 & - & - & - & 0.98 & 76 & 148 \\
\hline $\begin{array}{l}\text { Feathertop } \\
\text { Rhodes Grass }\end{array}$ & 0.5 & 0.045 & 41.02 & - & - & - & 0.99 & 41 & 61 \\
\hline Fleabane & 0.52 & 0.04 & 37.57 & - & - & - & 0.99 & 39 & 61 \\
\hline Marshmallow & 0.55 & 0.0064 & 150.1 & - & - & - & 0.98 & 163 & 297 \\
\hline Paddy Mellon & 0.52 & 0.047 & 33.92 & - & - & - & 0.99 & 35 & 53 \\
\hline Wild Oats & 0.54 & 0.024 & 41.23 & - & - & - & 0.97 & 44 & 80 \\
\hline Wild Radish & 0.52 & 0.017 & 64.53 & - & - & - & 0.99 & 67 & 118 \\
\hline
\end{tabular}


about 15 - $20 \mathrm{~mm}$ above the ground. With this arrangement, the trailer was towed over short sections of Kikuyu grass (Pennisetum clandestinum).

The treated sections were about 1.5 to $2.0 \mathrm{~m}$ long, on flat surfaces, to avoid accidental damage to the wave-guides due to engagement with the soil surface. The travel time for these strips was between 7 and 10 seconds, equating to about $720 \mathrm{~m} \mathrm{~h}^{-1}$. The treated strips were evaluated about 4 days after treatment. Only one of the four microwave generators were used during these experiments.

Thermal images revealed that the grass achieved a maximum temperature of $61^{\circ} \mathrm{C}$ (Figure 8.5). There was audible crackling of the grass as the applicator moved along the strip, indicating that micro-steam explosions were occurring in the grass stems due to rapid microwave heating (Brodie, 2007; Brodie et al., 2011). The grass was wet and wilted immediately after treatment (Figure 8.6), and there was evidence of scorching later, on the same day that the treatment was applied. After four days, the treated strips were quite evident in the grassed area (Figure 8.7). There was $100 \%$ control of the grass along all treated strips, with the treated strip being $100 \mathrm{~mm}$ wide.

Based on using a $2 \mathrm{~kW}$ microwave generator to treat a strip $720 \mathrm{~m}$ long by $0.1 \mathrm{~m}$ wide in one hour, the energy density for this treatment is equivalent to $10 \mathrm{~J} \mathrm{~cm}^{-2}$ for $100 \%$ control of Kikuyu grass.

Other experiments, involving ryegrass and general weedy areas with multiple species have been conducted with the new antenna, with the same results.

The purpose of this experiment was to demonstrate mobility of the system. It is apparent from the results that movement of the applicator over the ground is possible and treatment is effective. The optimal operating speed of the system over grass covered ground is yet to be determined; however, these results are very encouraging. The optimal travel speed is yet to be determined; however, there was $100 \%$ plant kill in all the test strips at this speed. It is also important to note that the treatment strips are very clearly defined in the grass; therefore, with the correct guiding technology, microwave treatment can be very selective and has no effect adjacent plants. This should lend itself to effective inter-row weed control, without affecting the adjacent crop.

\subsection{Conclusion}

Microwave treatment can kill weed plants, above the soil surface. Static experiments indicate that the required energy varies considerably from species to species. The average lethal dose needed to $90 \%$ efficacy across all the tested species (Tab. 8.1) is 137 $\mathrm{J} \mathrm{cm}^{-2}$; however, the early experiments with the novel antenna indicate that $10 \mathrm{~J} \mathrm{~cm}^{-2}$ is sufficient to kill emerged plants using this system. This equates to $1.0 \mathrm{GJ} \mathrm{ha}^{-1}$. This is comparable to the total energy associated with herbicide weed management (see Chapter 4). Allowing an efficiency of between 75 and 90\% for conversion of electrical energy into microwave energy, this equates to a treatment energy of between 1.1 and $1.3 \mathrm{GJ} \mathrm{ha}^{-1}$. 


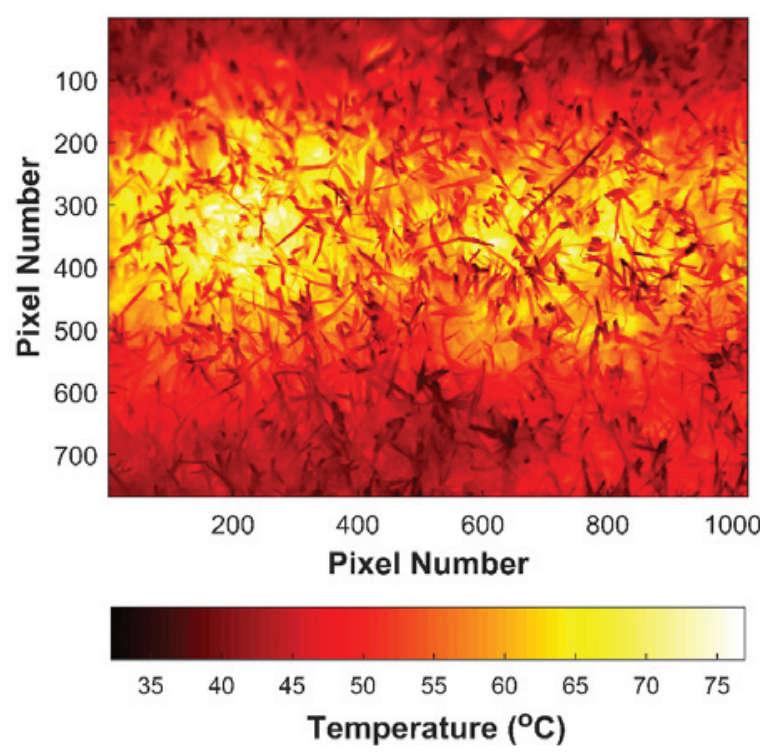

Figure 8.5: Thermal image of treated strip (Treatment $=1.5 \mathrm{~m}$ in 7 seconds), immediately after treatment.

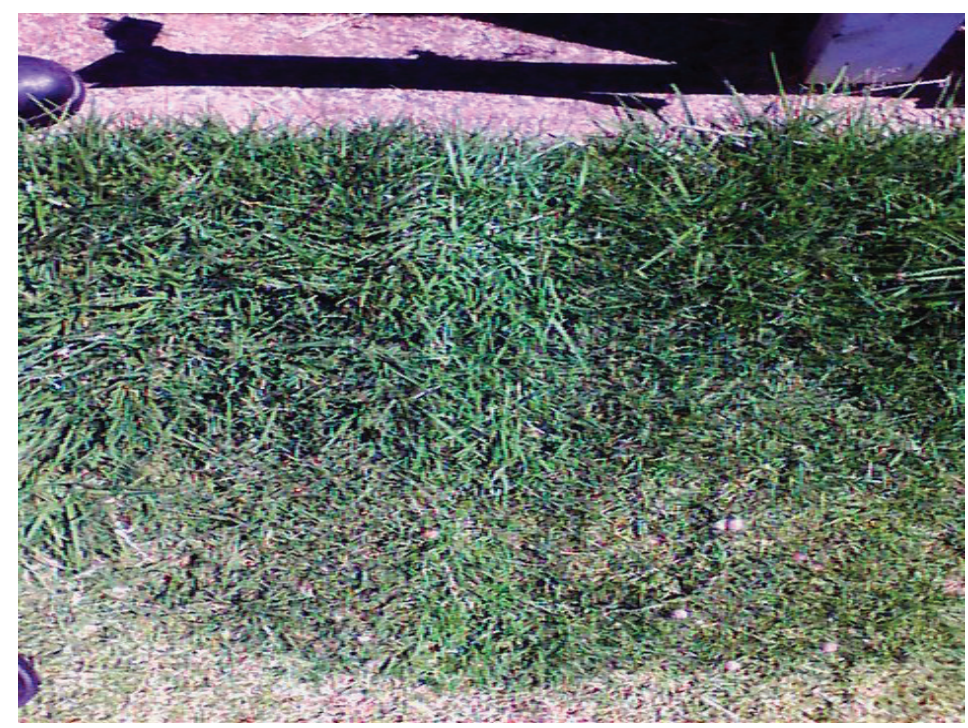

Figure 8.6: Visible light image of the treated strip, shown in Figure 8.5. 


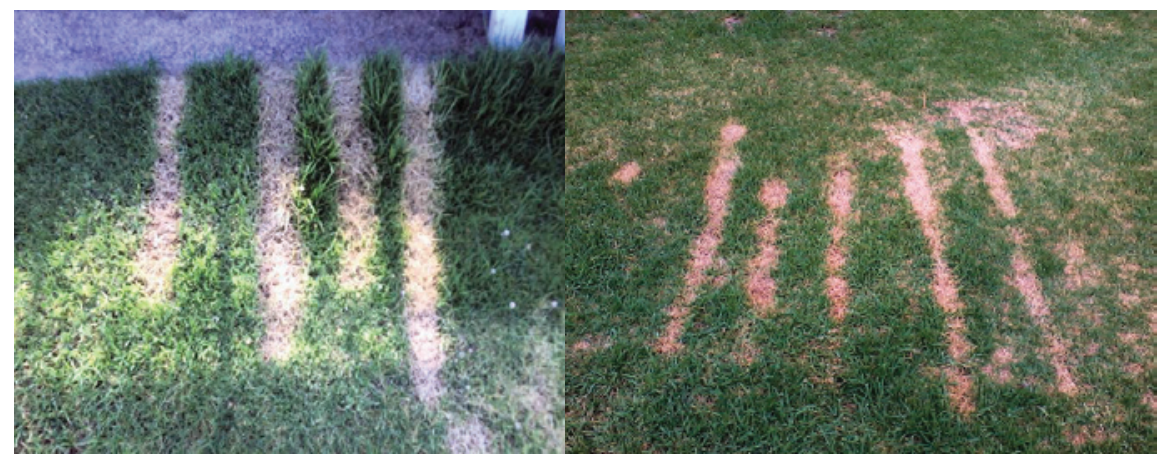

Figure 8.7: Image of four treated strips of kikuyu grass, taken (left) 4 days after treatment and (right) 20 days after treatment.

\subsection{References}

Ark, P. A., \& Parry, W. (1940). Application of High-Frequency Electrostatic Fields in Agriculture. The Quarterly Review of Biology, 15(2), 172-191.

Bebawi, F. F., Cooper, A. P., Brodie, G. I., Madigan, B. A., Vitelli, J. S., Worsley, K. J., \& Davis, K. M. (2007). Effect of microwave radiation on seed mortality of rubber vine (Cryptostegia grandiflora R.Br.), parthenium (Parthenium hysterophorous L.) and bellyache bush (Jatropha gossypiifolia L.). Plant Protection Quarterly, 22(4), 136-142.

Brodie, G. (2007). Microwave treatment accelerates solar timber drying. Transactions of the American Society of Agricultural and Biological Engineers, 50(2), 389-396.

Brodie, G., Botta, C., \& Woodworth, J. (2007). Preliminary investigation into microwave soil pasteurization using wheat as a test species. Plant Protection Quarterly, 22(2), 72-75.

Brodie, G., Hamilton, S., \& Woodworth, J. (2007). An assessment of microwave soil pasteurization for killing seeds and weeds. Plant Protection Quarterly, 22(4), 143-149.

Brodie, G., Harris, G., Pasma, L., Travers, A., Leyson, D., Lancaster, C., \& Woodworth, J. (2009). Microwave soil heating for controlling ryegrass seed germination. Transactions of the American Society of Agricultural and Biological Engineers, 52(1), 295-302.

Brodie, G., \& Hollins, E. (2015). The Effect of Microwave Treatment on Ryegrass and Wild Radish Plants and Seeds. Global Journal of Agricultural Innovation, Research \& Development, 2(1), 16-24.

Brodie, G., Jacob, M. V., Sheehan, M., Yin, L., Cushion, M., \& Harris, G. (2011). Microwave modification of sugar cane to enhance juice extraction during milling. Journal of Microwave Power and Electromagnetic Energy, 45(4), 178-187.

Brodie, G., Ryan, C., \& Lancaster, C. (2012). The effect of microwave radiation on Paddy Melon (Cucumis myriocarpus). International Journal of Agronomy, 2012, 1-10.

Brodie, G., Torkovnikov, G., \& Farrell, P. (2016). Australia Patent No. 2016905272. A. P. Office.

Diprose, M. F., Benson, F. A., \& Willis, A. J. (1984). The Effect of Externally Applied Electrostatic Fields, Microwave Radiation and Electric Currents on Plants and Other Organisms, with Special Reference to Weed Control. Botanical Review, 50(2), 171-223.

Grundler, W., Keilmann, F., \& Fröhlich, H. (1977). Resonant growth rate response of yeast cells irradiated by weak microwaves. Physics Letters A, 62(6), 463-466. doi:https://doi. org/10.1016/0375-9601(77)90696-X 
Hightower, N. C., Burdette, E. C., \& Burns, C. P. (1974). Investigation of the use of microwave energy for weed seed and wood products insect control, Final Technical report. Project E-230-901. Retrieved from

Horikoshi, S., Hasegawa, Y., \& Suzuki, N. (2017). Benefitting of Plants Using Microwave Genetic Activation Method and its Applications. Paper presented at the IMPI's 51st Annual Microwave Power Symposium (IMPI 51), Miami, FL, USA.

Magone, I. (1996). The effect of electromagnetic radiation from the Skrunda radio location station on Spirodela polyrhiza (L.) Schleiden cultures. Science of theTotal Environment, 180(1), 75-80.

Petrov, I. Y., Moiseeva, T. V., \& Morozova, E. V. (1991). A possibility of correction of vital processes in plant cell with microwave radiation. Paper presented at the 1991 IEEE International Symposium on Electromagnetic Compatibility, Cherry Hill, NJ, USA.

Skiles, J. W. (2006). Plant response to microwaves at $2.45 \mathrm{GHz}$. Acta Astronautica, 58(5), 258-263. doi:DOI: 10.1016/j.actaastro.2005.12.007

Wayland, J., Merkle, M., Davis, F., Menges, R. M., \& Robinson, R. (1975). Control of weeds with UHF electromagnetic fields. Unkrautbekämpfung mit elektromagnetischen UHF-Feldern., 15(1), 1-5.

Zapata-Sierra, A. J., \& Manzano-Agugliaro, F. (2017). Controlled deficit irrigation for orange trees in Mediterranean countries. Journal of Cleaner Production, 162(Supplement C), 130-140.

doi:https://doi.org/10.1016/j.jclepro.2017.05.208 